\title{
Antimicrobial Bacterial Cellulose-Silver Nanoparticles Composite Membranes
}

\author{
Hernane S. Barud, ${ }^{1}$ Thaís Regiani, ${ }^{1}$ Rodrigo F. C. Marques, ${ }^{2}$ Wilton R. Lustri, ${ }^{3}$ \\ Younes Messaddeq, ${ }^{1}$ and Sidney J. L. Ribeiro ${ }^{1}$
}

${ }^{1}$ Institute of Chemistry, São Paulo State University (UNESP), 14801-970 Araraquara, SP, Brazil

${ }^{2}$ Instituto de Ciência e Tecnologia (ICT), Universidade Federal de Alfenas (UNIFAL-MG), Campus Avançado de Poços de Caldas, Rua Gabriel Monteiro da Silva, 37130-000 Alfenas, MG, Brazil

${ }^{3}$ Uniara, 14801-320 Araraquara, SP, Brazil

Correspondence should be addressed to Hernane S. Barud, hernane.barud@gmail.com

Received 13 December 2010; Accepted 21 February 2011

Academic Editor: Edward Andrew Payzant

Copyright ( $) 2011$ Hernane S. Barud et al. This is an open access article distributed under the Creative Commons Attribution License, which permits unrestricted use, distribution, and reproduction in any medium, provided the original work is properly cited.

\begin{abstract}
Antimicrobial bacterial cellulose-silver nanoparticles composite membranes have been obtained by "in situ" preparation of Ag nanoparticles from hydrolytic decomposition of silver nitrate solution using triethanolamine as reducing and complexing agent. The formation of silver nanoparticles was evidenced by the X-ray diffraction, scanning electron microscopy (SEM), transmission electron microscopy (TEM), and absorption in the UV-Visible (350 $\mathrm{nm}$ to $600 \mathrm{~nm}$ ). Thermal and mechanical properties together with swelling behavior for water were considered. TEA concentration was observed to be important in order to obtain only Ag particles and not a mixture of silver oxides. It was also observed to control particle size and amount of silver contents in bacterial cellulose. The composite membranes exhibited strong antimicrobial activity against Gram-negative and Gram-positive bacteria.
\end{abstract}

\section{Introduction}

Bacterial cellulose (BC) is a nanomaterial produced by various strains of Acetobacter species and also strains of pseudomonas, Achrobacter, Alcaligene, Aerobacter, and Azotobacter [1]. Acetobacter xylinum (or Gluconacetobacter xylinus) is one of the species capable to produce cellulose in large scale in culture medium containing carbon and nitrogen sources in either static or agitated environment.

$\mathrm{BC}$ is formed by a network of ribbon-shaped cellulose fibrils that are less than $100 \mathrm{~nm}$ wide and made of microfibrils $2-4 \mathrm{~nm}$ in diameter [2].

In terms of the molecular formula, $\mathrm{BC}$ is identical to cellulose of plant origin-apart from alien groups such as carbonyl and carboxyl units in the latter as a result of the plant cellulose processing. However, important structural features and properties, significant for practical application of $\mathrm{BC}$, are quite different from wood cellulose: high purity, high degree of polymerization (up to 8000), high crystallinity (of 70 to $80 \%$ ), high water content to $99 \%$, and high mechanical stability [3].

As a consequence of the special properties, a diversity of applications are proposed as industry of paper and textiles, diaphragms for electroacoustic transducers, paint additives, coatings, pharmaceuticals and cosmetics, optically transparent composites, substrates for OLEDs, e-paper and as biomaterials in cosmetics and medicine [3-5].

In fact, one of the most promising areas of $\mathrm{BC}$ application as biomaterials is the utilization as a temporary skin substitute in the therapy of difficult wounds, burns, and ulcers. However, BC itself has no antimicrobial activity to prevent wound infection [4].

In this sense, recently, a great effort has been devoted to the development of antimicrobial $\mathrm{BC}$ membranes especially silver particles containing $\mathrm{BC}[6-8]$.

Silver has been known to exhibit strong cytotoxicity towards a broad range of micro-organisms, based on oligodynamic effect, that is, silver ions are capable of causing 
a bacteriostatic (growth inhibition) or even a bactericidal (antibacterial) impact [9].

In a previous work, "in situ" preparation of silver nanoparticle containing $\mathrm{BC}$ membranes was shown with the hydrolytic decomposition of silver nitrate using triethanolamine (TEA) complexes. The utilization of TEA as stabilizer and reducing agent leads to spherical particles well dispersed on the $\mathrm{BC}$ bulk ultrafine reticulated structure. Therefore, a mixture of $\mathrm{Ag}$ and $\mathrm{Ag}$ oxides was, in fact, obtained due to low TEA content [10].

In this work, a systematic study involving the hydrolytic decomposition of silver nitrate solution at different triethanolamine (TEA) concentrations is presented. Antimicrobial tests for the BC-silver nanoparticles composite membranes were also considered.

\section{Material and Methods}

2.1. Bacterial Cellulose Membranes. Never dried bacterial cellulose (4 $\mathrm{mm}$ thick) membranes were supplied from Fibrocel-Produtos Biotecnológicos LTDA-Brazil.

2.2. BC-Silver Nanoparticles Composites Preparation. Bacterial cellulose membranes $\left(6 \mathrm{~cm}^{2}\right)$ were soaked in $15 \mathrm{~mL}$ of $0.01 \mathrm{~mol} \cdot \mathrm{L}^{-1} \mathrm{AgNO}_{3}$ solution, followed by the addition of $0.1 \mathrm{~mL}$ of TEA solutions with different concentrations $\left(0.01 \mathrm{~mol} \cdot \mathrm{L}^{-1}, 0.1 \mathrm{~mol} \cdot \mathrm{L}^{-1}\right.$ and $\left.1.0 \mathrm{~mol} \cdot \mathrm{L}^{-1}\right)$. The mixtures were kept for 12 hours. After that, samples were washed several times in $30 \%$ ethanol solution. Silver-containing BC membrane membranes were dried at $80^{\circ} \mathrm{C}$ for 24 hours.

\subsection{Characterization}

2.3.1. X-Ray Diffraction (XDR). XRD patterns were obtained in a Siemens Kristalloflex diffractometer using nickel-filtered $\mathrm{Cu} \mathrm{K} \alpha$ radiation, step pass of $0.02^{\circ}$ and a step time of $3 \mathrm{~s}$, from 4 to $70^{\circ}$ ( $2 \theta$ angle).

2.3.2. Scanning Electron Microscopy. Scanning electron microscope images were obtained with an FEG-SEM JSM 6330F at the LNLS (Brazilian Synchroton Light Laboratory). Samples were coated with a thick carbon layer.

2.3.3. Transmission Electron Microscopy (TEM). TEM measurements were obtained in a JEOL 200CX microscopy, operating at $200 \mathrm{kV}$. The samples were heated at $600^{\circ} \mathrm{C}$ degrees to remove bacterial cellulose. The residue formed by silver nanoparticles was suspended in ethanol. A drop of the suspension was deposited on the copper grid. The information was added in the text. A drop of the suspension was deposited on the copper grid.

2.3.4. Thermogravimetric (TG) Curves. Thermal gravimetric (TG) curves were obtained for dried samples in an SDT 2960 equipment from TA-Instruments. Samples were heated in open alumina pans from $40^{\circ} \mathrm{C}$ to $600^{\circ} \mathrm{C}$, under synthetic air with flux of $50 \mathrm{~mL} \mathrm{~min}{ }^{-1}$, at heating rate of $10^{\circ} \mathrm{C} / \mathrm{min}$.

2.3.5. UV-VIS. UV-V absorption spectra were obtained in a Varian Cary 500 Scan spectrometer. Pure and dry cellulose

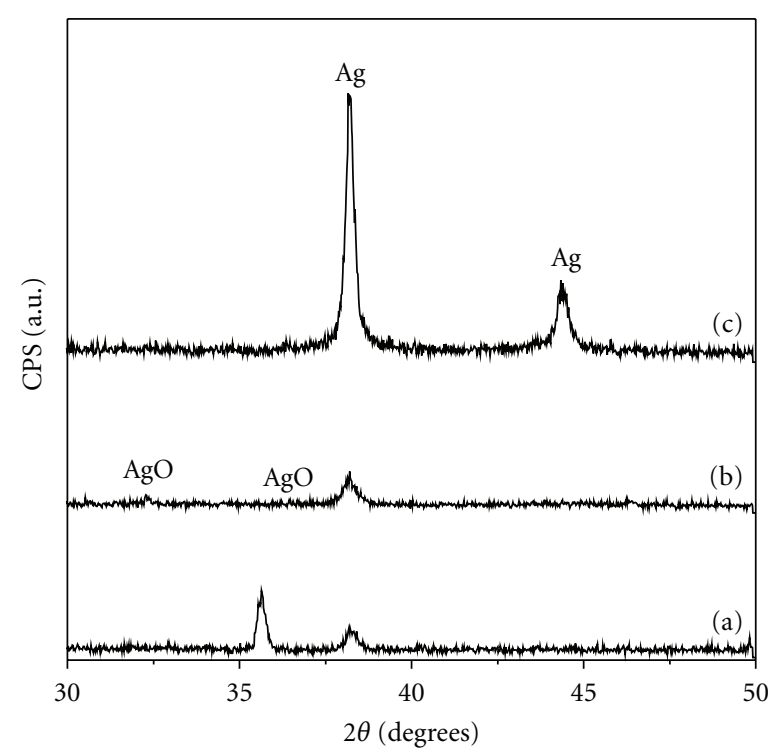

FIgURE 1: X-rays diffraction patterns of BC-Ag-TEA membranes. (a) BC-TEA $0.01 \mathrm{~mol} \cdot \mathrm{L}^{-1}$, (b) BC-TEA $0.1 \mathrm{~mol} \cdot \mathrm{L}^{-1}$, and (c) BCTEA $1.0 \mathrm{~mol} \cdot \mathrm{L}^{-1}$.

membranes were used as references in an appropriate support for solid samples.

2.3.6. Swelling. BC and BC-Ag-TEA membranes, dried to constant weight, were cut into disc shapes with $1.5 \mathrm{~cm}$ diameter and immersed in deionized water for different times at room temperature. Swelling was calculated as follows:

$$
\text { Swelling }=\frac{\left(G_{s, t}-G_{i}\right)}{G_{i}},
$$

where $G i$ is the initial weight of dried sample and $G_{s, t}$ is the weight of sample in swollen state.

2.3.7. Mechanical Properties. The mechanical measurements were performed with a dynamic mechanical analyzer (DMA) 2980 (TA Instruments) equipped with a film tension clamp at $27^{\circ} \mathrm{C}$. The specimens dimensions were $30.50 \mathrm{~mm} \times 6.20 \mathrm{~mm}$ $\times 0.15 \mathrm{~mm}$ (length $\times$ width $\times$ thickness). A preload force of $0.01 \mathrm{~N}$ was used and the force ramp $8 \mathrm{~N} \mathrm{~m}^{-1}$ until the rupture of sample. The device was previously calibrated, and a total of 5 measurements for each sample were made in order to ensure the reproducibility of the results.

2.3.8. Antimicrobial Activity Studies. Antimicrobial activities have been investigated against Pseudomonas aeruginosa ATCC-27853 and Escherichia coli ATCC 25922 as models for Gram-negative bacteria and Staphylococcus aureus ATCC 25923 as model for Gram-positive bacteria. The antimicrobial activity was evaluated by the disc diffusion method in Mueller-Hinton $(\mathrm{MH})$ agar plates. The microorganisms were cultivated in tubes containing $3 \mathrm{~mL}$ of sterile brain heart infusion (BHI) and incubated for $18 \mathrm{~h}$ at $35^{\circ} \mathrm{C}-37^{\circ} \mathrm{C}$. Sufficient inoculum was added in new tubes until turbidity of 


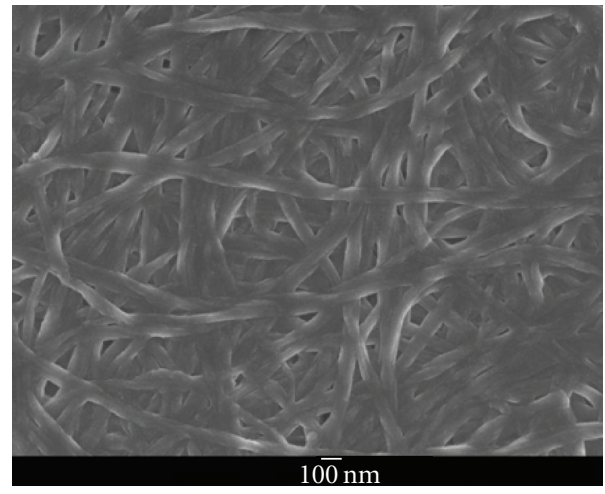

(a)

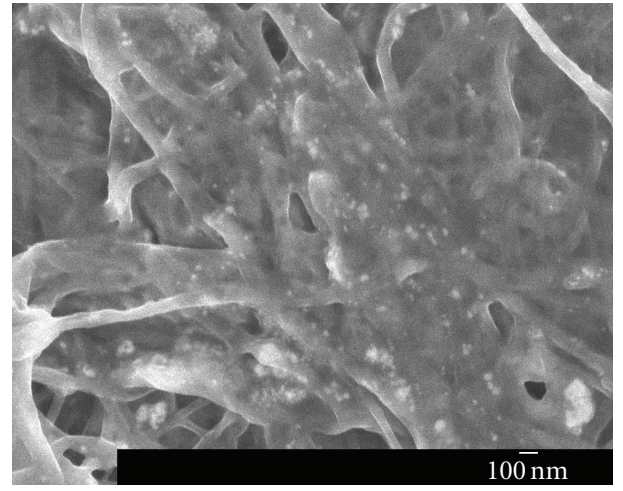

(b)

Figure 2: SEM images of: (a) Pure BC membrane and (b) BC-Ag-TEA $1 \mathrm{~mol} \cdot \mathrm{L}^{-1}$.

$0.5 \mathrm{McF}$ arland $\left(\sim 10^{8} \mathrm{CFU} / \mathrm{mL}\right)$. The new bacterial inoculum was uniformly spread using sterile cotton swabs on sterile Petri dishes MH agar. Sample membranes were cut into disc shapes of $1.5 \mathrm{~cm}$ diameter and UV sterilized for 2 hours. After sterilization, the discs were placed on the bacterial culture, and the plates were incubated for $18 \mathrm{~h}$ at $35^{\circ} \mathrm{C}-37^{\circ} \mathrm{C}$. Clear zones of inhibition formed around the discs were measured.

\section{Results and Discussion}

3.1. X-Ray Diffraction (XRD). Figure 1 shows XRD patterns of BC-Ag-TEA membranes.

Figure 1(a) shows the XRD pattern obtained for the sample with the smallest concentration of TEA. A diffraction band is observed at $32.3^{\circ}$ and can be attributed to $\mathrm{AgO}$ or $\mathrm{Ag}_{2} \mathrm{O}$ phases. The same behavior was observed for the sample BC-Ag-TEA $0.1 \mathrm{~mol} \cdot \mathrm{L}^{-1}$ (Figure $1(\mathrm{~b})$ ) with a small decrease in the relative intensity of the line assigned to the oxides mixture.

Figure 1(c) shows the XRD pattern obtained for the sample BC-Ag-TEA $1 \mathrm{~mol} \cdot \mathrm{L}^{-1}$. The two diffraction bands at $38.3^{\circ}$ and $44.5^{\circ}$ can be attributed to metallic silver corresponding to the crystallographic planes (111) and (220), respectively $[6,10]$. The band corresponding to the oxide mixture is not observed, confirming, therefore, the influence of the concentration of TEA in obtaining metallic silver.

As discussed in our preview paper [10], the formation of Ag nanoparticles on BC fibers can be explained in terms of the interaction with cellulose hydroxyl groups. Despite of the fact that cellulose structure exhibits aldehyde hydrates reducing terminal groups, no metallic silver peak could be observed in XRD patterns of membranes prepared only from $\mathrm{BC}$ and $\mathrm{Ag}^{+}$solutions. Diffusion of hydrated silver ions $\left[\mathrm{Ag}\left(\mathrm{H}_{2} \mathrm{O}\right)_{2}\right]^{+}$into bacterial cellulose matrix leads to coordination with the different cellulose hydroxyl groups. In general, the reducing action of different agents (UV radiation, sodium boron hydride, hypophosphite, hydrazine, hydroxylamine, ascorbic acid, among others) is required [11-14].

In this work, the additional interaction with TEA should lead to a more complex reduction mechanism. TEA molecules act simultaneously as a strong reducing agent and chelating agent, influencing the nucleation and particle growth, hence particle size. Hydrolytic decomposition of Ag-TEA complexes in aqueous solutions at around $50^{\circ} \mathrm{C}$ is known to lead to $\mathrm{Ag}$ and $\mathrm{AgO}$ thin films [15]. TEA acts as a tridentate ligand through two of the three hydroxyl $\mathrm{O}$ atoms together with the amine $\mathrm{N}$ atom. $\mathrm{Ag}^{+}$is reduced to $\operatorname{Ag}(0)_{2}$, and as these particles are formed, they act as a catalyst for the reduction of the remaining metal ions present in the bulk solution leading to $\operatorname{Ag}(0) n$ cluster growth. The aggregation process does not cease until all metal ions in solutions are consumed, resulting in larger particles [15]. The hydrolytic decomposition of the Ag-TEA complexes leads to silver particles formation stabilized on the $\mathrm{BC}$ fibrils. Moreover, depending on the $\mathrm{Ag}^{+}$and TEA relative contents, $\mathrm{Ag}^{+}$ions could be sandwiched by two TEA molecules. Intraand intermolecular hydrogen bonding among hydroxyl TEA groups could lead to a three-dimensional network and the decomposition of this three-dimensional complex network allows precipitation of spherical particles on $\mathrm{BC}$ surface.

The observation of $\mathrm{AgO}$ phase in XRD diffraction pattern corroborates the decomposition mechanism for AgTEA complexes proposed in [15], since the low TEA/silver concentration should lead to a $\mathrm{Ag}(0)-\mathrm{AgO}$ mixture. In fact, XRD analyses confirms that TEA concentration is very important in order obtain only Ag particles, as observed in the BC-Ag-TEA $1 \mathrm{~mol} \cdot \mathrm{L}^{-1}$ diffraction pattern [15].

3.2. SEM and TEM Images. Figure 2 shows SEM images of pure bacterial cellulose and a representative image for BCAg-TEA composite.

The dried BC membrane, Figure 2 (a) shows a $3 \mathrm{D}$ network structure composed by long cellulose nanofibers.

BC-Ag-TEA $1 \mathrm{M}$ membrane, Figure 2(b) shows well dispersed spherical silver particles (white spots) attached to the $\mathrm{BC}$ membrane and adsorbed on the fibrils surface, and this image suggest that BC fibrils appear swollen most probably by TEA presence.

Figure 3 shows TEM images and histograms obtained for BC-Ag-TEA samples. Spherical nanoparticles were obtained for all TEA concentrations. Bigger particles are obtained with increasing TEA content. In fact, smaller mean particle size 

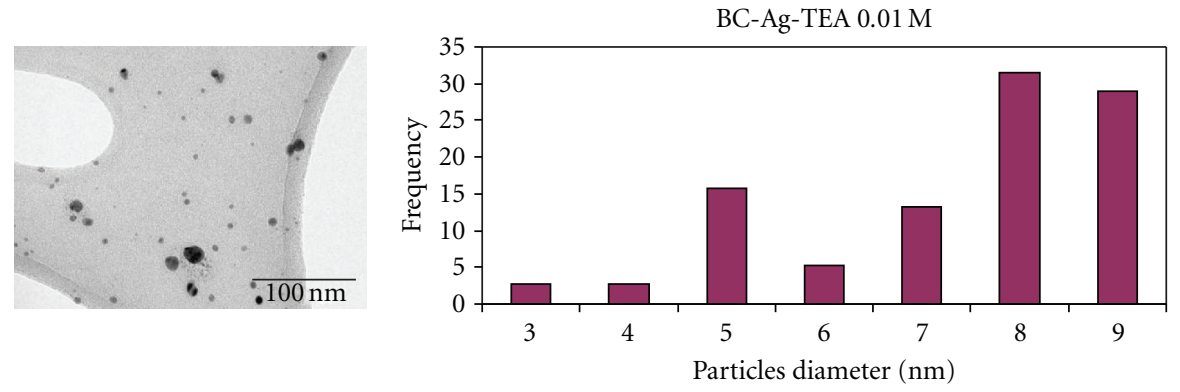

(a)
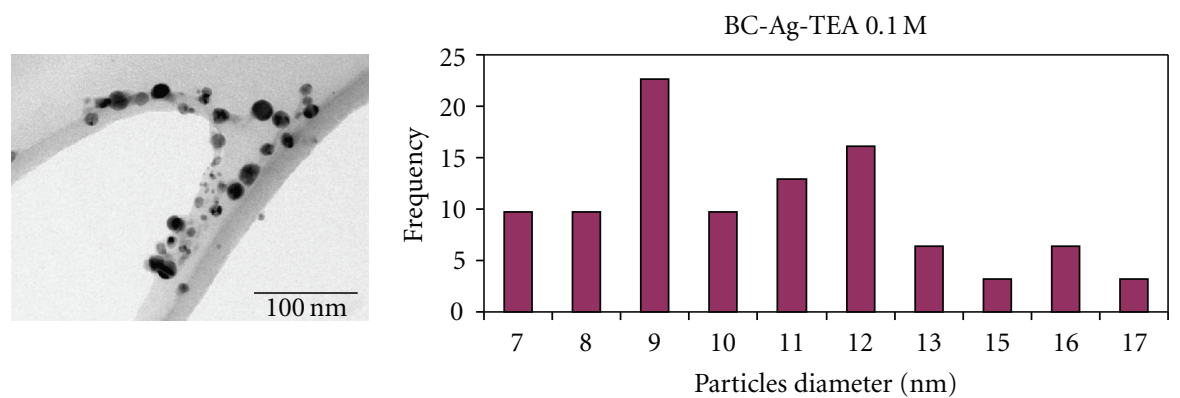

(b)
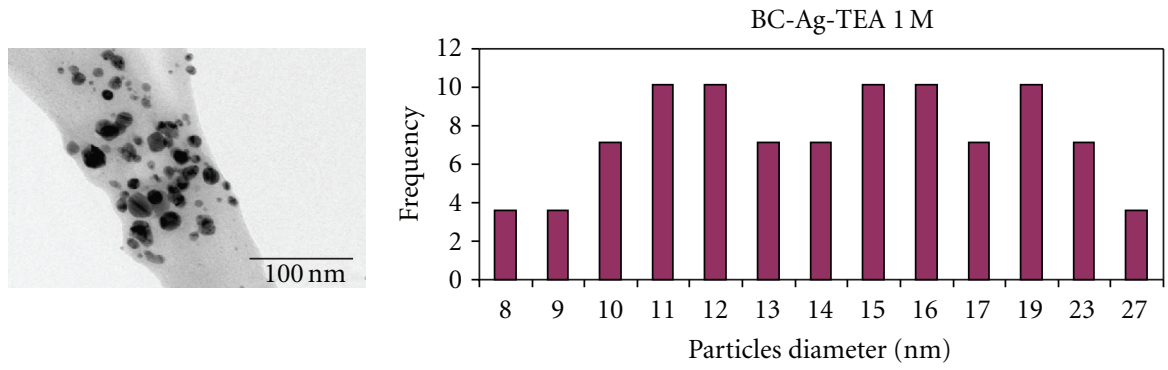

(c)

FIgure 3: TEM images and respective histograms: (a) BC-Ag-TEA $0.01 \mathrm{~mol} \cdot \mathrm{L}^{-1}$; (b) BC-Ag-TEA $0.1 \mathrm{~mol} \cdot \mathrm{L}^{-1}$; (c) BC-Ag-TEA $1 \mathrm{~mol} \cdot \mathrm{L}^{-1}$.

$(8 \mathrm{~nm})$ is observed for BC-Ag-TEA $0.01 \mathrm{~mol} \cdot \mathrm{L}^{-1}$ membranes while particles with mean size of $15 \mathrm{~nm}$ are observed for BC-Ag-TEA $1 \mathrm{~mol} \cdot \mathrm{L}^{-1}$ membrane. According to Rira Jung, the increase in particles size observed with the increase in the TEA content phenomenon should occur, because the reduction rate observed for the higher TEA concentration is relatively higher than the adsorption rate of the formed silver nanoparticles on cellulose nanofibrils. Therefore, the newly reduced silver nanoparticles might form aggregates with silver crystals that had already been adsorbed on the cellulose nanofibrils [7].

3.3. Thermal Gravimetric (TG) Analyses. Figure 4 shows the thermal behavior of the $\mathrm{BC}$ and BC-Ag-TEA membranes.

A continuous mass loss $(5-10 \%)$ is observed for pure $\mathrm{BC}$, in the temperature range between $50^{\circ} \mathrm{C}$ until $150^{\circ} \mathrm{C}$, due to evaporation of the superficial water. Thermal degradation occurs in two steps at approximately $330^{\circ} \mathrm{C}$ and $460^{\circ} \mathrm{C}$ [2].

The BC-Ag-TEA $0.01 \mathrm{~mol} \cdot \mathrm{L}^{-1}$ membrane presents similar behavior. The low Ag-TEA content does not lead to important changes in TG curve.

A different thermal profile is observed for BC-Ag membranes containing higher concentration of TEA complex. The mass loss due to water evaporation is no longer observed for temperatures up to $110^{\circ} \mathrm{C}$. New mass loss events (around 30\%) are observed up to 250 degrees for BC-AgTEA $0.1 \mathrm{~mol} \cdot \mathrm{L}^{-1}$ and BC-Ag-TEA $1 \mathrm{~mol} \cdot \mathrm{L}^{-1}$ that must be associated to water evaporation and TEA evaporation and degradations [16].

From TG curves carried out in static air, the residual mass could be used to estimate the silver contents into BC membrane. The inset in Figure 5 shows increasing silver particles content with the increase in TEA concentrations. 


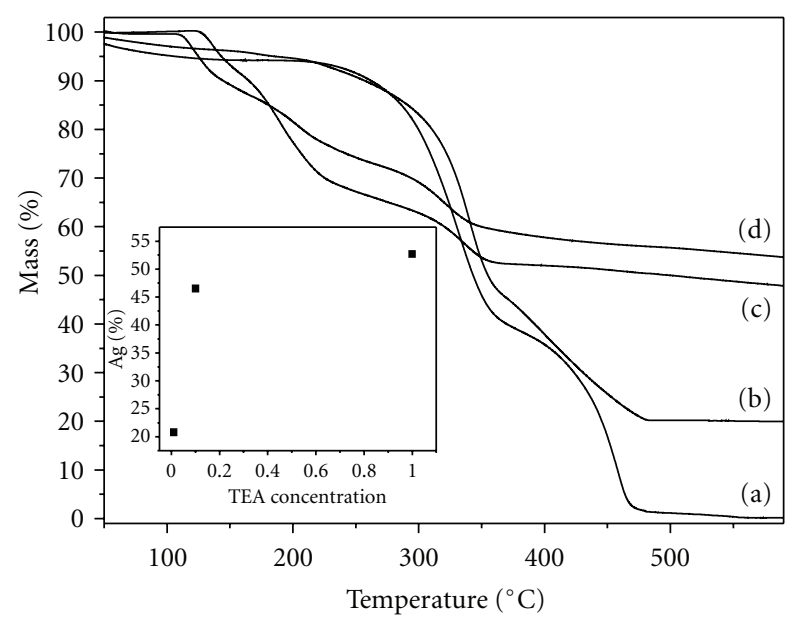

Figure 4: TG curves for: (a) BC; (b) BC-Ag-TEA $0.01 \mathrm{~mol} \cdot \mathrm{L}^{-1}$; (c) BC-Ag-TEA $0.1 \mathrm{~mol} \cdot \mathrm{L}^{-1}$; (d) BC-Ag-TEA $1 \mathrm{~mol} \cdot \mathrm{L}^{-1}$. The inset shows the Ag content (\%) in the membranes as a function of TEA concentration used in the preparation procedure.

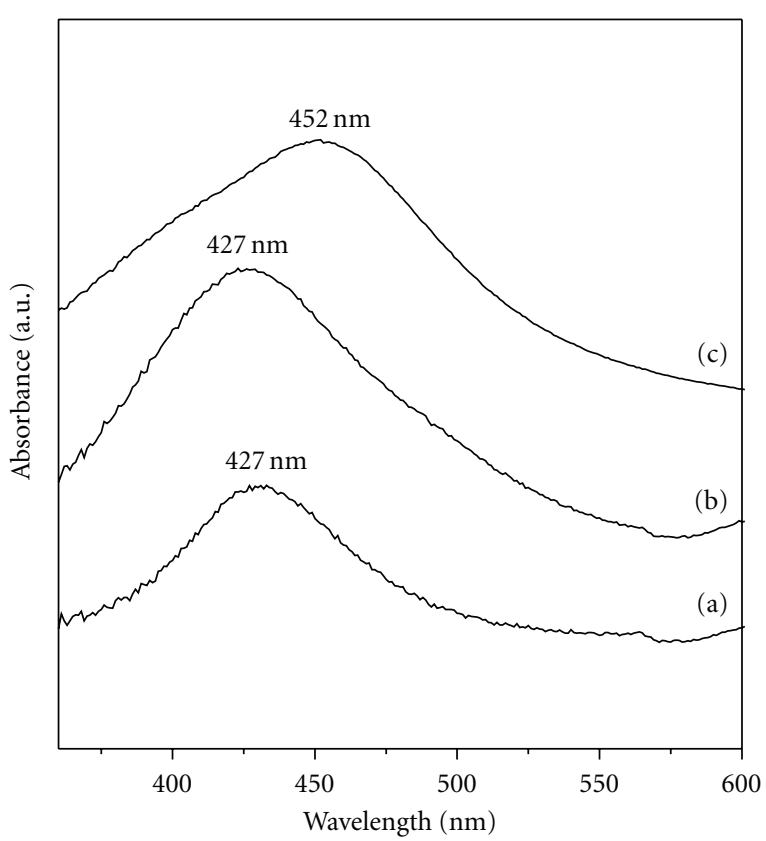

FIgURE 5: Absorption spectra of silver nanoparticle bacterial cellulose membranes. (a) BC-Ag-TEA $0.01 \mathrm{~mol} \cdot \mathrm{L}^{-1}$; (b) BC-AgTEA $0.1 \mathrm{~mol} \cdot \mathrm{L}^{-1}$; (c) BC-Ag-TEA $1 \mathrm{~mol} \cdot \mathrm{L}^{-1}$.

The results show clearly the important role of TEA in the silver adsorption process.

\subsection{UV-VIS. Figure 5 shows absorption spectra.}

The color of BC-Ag-TEA composites changed from yellow-brown to black with increase on TEA concentration and consequently due to the increases on silver content $[17,18]$.

The typical absorption of metallic silver nanoparticles was observed for all samples, related to the surface plasmon

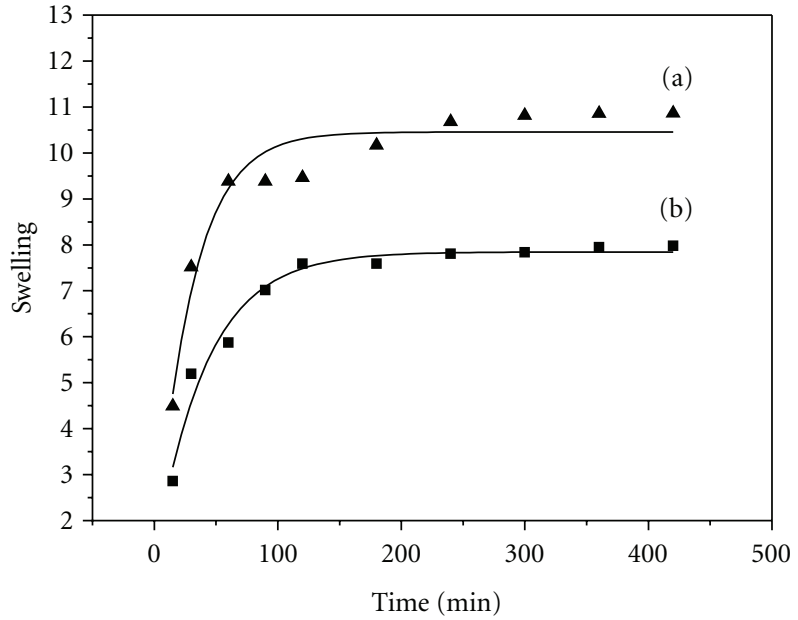

FIGURE 6: Swelling ability of (a) BC pure membrane; (b) BC-AgTEA $1 \mathrm{~mol} \cdot \mathrm{L}^{-1}$ membrane.

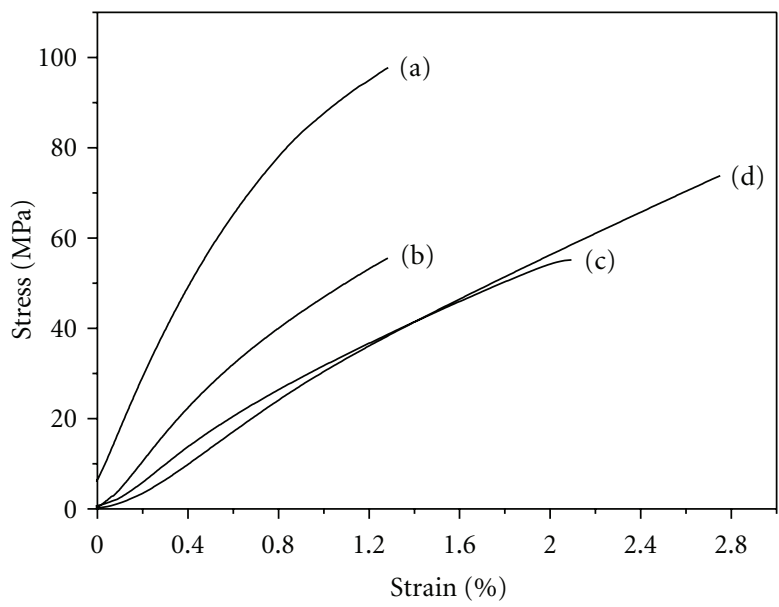

Figure 7: Stress $\times$ strain curves: (a) Pure BC membrane; (b) BCAg-TEA $0.01 \mathrm{~mol} \cdot \mathrm{L}^{-1}$; (c) BC-Ag-TEA $0.1 \mathrm{~mol} \cdot \mathrm{L}^{-1}$; (d) BC-AgTEA $1 \mathrm{~mol} \cdot \mathrm{L}^{-1}$.

resonance (SPR) of conducting electron (or free electron) on the surface of silver nanoparticles. Maxima are observed at $427 \mathrm{~nm}$ for BC-Ag-TEA $0.01 \mathrm{~mol} \cdot \mathrm{L}^{-1}$ and BC-Ag-TEA $0.1 \mathrm{~mol} \cdot \mathrm{L}^{-1}$ membranes and at $452 \mathrm{~nm}$ for the BC-AgTEA $1 \mathrm{~mol} \cdot \mathrm{L}^{-1}$ sample. Broadening and red shift of the absorption band observed for the membrane obtained with the higher TEA content may be associated with the increase in a particle size and size distribution $[6,17,18]$.

3.5. Swelling. Figure 6(a) and (b) show swelling (deionized water) observed for BC and CB-Ag-TEA $1 \mathrm{~mol} \cdot \mathrm{L}^{-1} \mathrm{mem}$ branes.

The main absorption occurs in the first two hours, and maximum swelling of 11 is observed for $\mathrm{BC}$ membrane, Figure 6(a). This behavior must be due to both chemical and physical structure of bacterial cellulose. BC is hydrophilic and it absorb a large amount of water; concerning the physical 


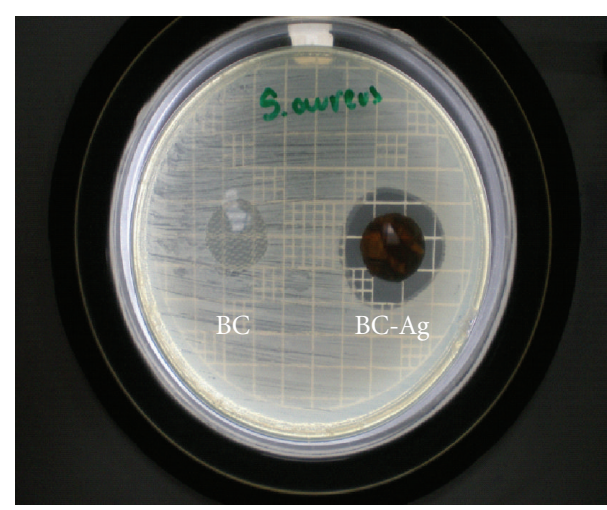

(a)

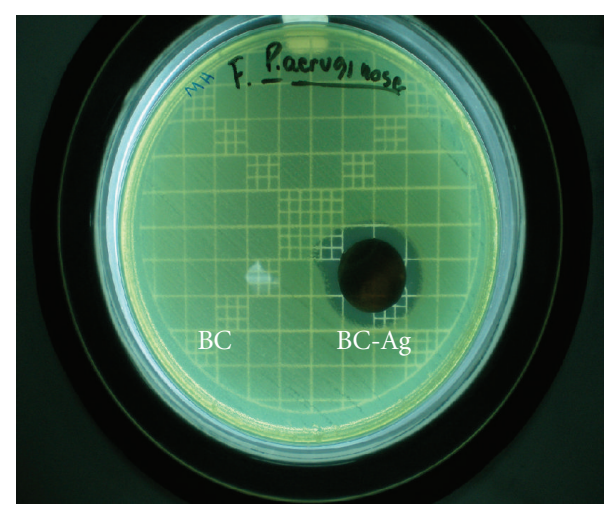

(b)

FIgure 8: Antimicrobial activity of BC-Ag-TEA 1 M: (a) Staphylococcus aureus; (b) Pseudomonas aeruginosa.

TABLE 1: Tensile modulus, tensile strength, and elongation at break of BC membrane and BC-Ag-TEA composites.

\begin{tabular}{lccr}
\hline Sample & Tensile modulus $(\mathrm{GPa})$ & Tensile strength $(\mathrm{MPa})$ & Elongation at break $(\%)$ \\
\hline (a) & 11 & $95.4 \pm 2.5$ & $1.2 \pm 0.2$ \\
(b) & 6 & $55.8 \pm 1.8$ & $1.3 \pm 0.3$ \\
(c) & 3 & $55.2 \pm 2.7$ & $2.0 \pm 0.7$ \\
(d) & 1.2 & $74.2 \pm 2.8$ & $2.8 \pm 0.2$ \\
\hline
\end{tabular}

structure, bacterial cellulose is $3 \mathrm{D}$ nonwoven network with large amount of pores generating the capillary forces contributing to water sorption [3].

Figure 6(b) shows the diminishing on the swelling ability (maximum swelling of 7) observed for the BC-Ag-TEA $1 \mathrm{~mol} \cdot \mathrm{L}^{-1}$ sample. The decrease in the capacity of absorption must refer to the reduction of the amounts of $\mathrm{BC}$ pores due to the incorporation of the silver nanoparticles and also to the plasticizer role observed for TEA containing samples which leads do reduction is swelling behavior. Swelling may also have been decreased due to unavailable hydrophilic groups (hydroxyl/aldehyde) which had reduced the silver and are no longer available to bind water. This plasticizer role of TEA is more clearly observed on mechanical properties shown hereafter.

3.6. Mechanical Properties. Figure 7 shows results for stressstrain measurements. Table 1 summarizes the derived results.

Pure BC membranes display good mechanical properties. High toughness is observed for BC-derived materials and composites due mainly to the nanofibrilar network structure and high mechanical nanofibril performance [19].

In fact, values of tensile modulus for single filaments of bacterial cellulose have been evaluated through AFM and Raman measurements and values of $78 \mathrm{GPa}$ and $114 \mathrm{GPa}$ have been obtained, respectively [20,21].

The curve obtained for the pure BC membrane, as shown in Figure 7(a), displays an initial linear behavior followed by a plastic behavior. The tensile modulus value obtained from the linear part of the curve is of $11 \mathrm{GPa}$ in accordance with results from the literature [22].

The observation of a plastic region is related to the breakdown within the fibers network during deformation and the rupture (tensile strenght) occurs at $98 \mathrm{MPa}$ with $1.2 \%$ elongation.

The addition of TEA lowers tensile modulus down to the value of $1.2 \mathrm{GPa}$ observed for the BC-Ag-TEA $1 \mathrm{~mol} \cdot \mathrm{L}^{-1}$ as shown in Table 1. Figure 8 also shows the plasticizer role played by TEA already observed for other polymer [23, 24].

More pronounced values are observed for the elongation at break as TEA content increases. For the samples studied, here the values are almost doubled with the addition of TEA. Tensile strength is observed to decrease. Comparing the samples containing TEA by increasing TEA content tensile strength is observed to increase.

3.7. Antimicrobial Activity Studies. Antimicrobial tests for all BC-Ag-TEA composites show strong antimicrobial activity against Gram-positive (Staphylococcus aureus) and Gramnegative (Escherichia coli and Pseudomonas aeruginosa) bacteria.

Figure 7 shows only a representative result for antimicrobial activity of the BC-Ag-TEA $1 \mathrm{~mol} \cdot \mathrm{L}^{-1}$ membrane toward Gram-positive and Gram-negative Staphylococcus aureus and Pseudomonas aeruginosa, respectively. An inhibition zone of $2 \mathrm{~cm}$ was observed confirming the diffusion of silver nanopartiles from BC-Ag-TEA composite to culture medium 
[18]. No inhibition zone was observed for the pure bacterial cellulose control.

The mechanism for microbial growth inhibition observed for silver is not entirely understood. Possible mechanisms involve the interaction of silver ions with biological macromolecules through proteins thiol groups $(-\mathrm{SH})$. Monovalent silver ions $\left(\mathrm{Ag}^{+}\right)$would replace $\left(\mathrm{H}^{+}\right)$ions of sulfhydryl or thiol groups, inactivating the protein, decreasing membrane permeability, and eventually causing cellular death. The reaction of monovalent silver with sulfhydryl groups produces a much more stable -S-Ag group only on the bacterial cell surface. Silver ions may not be capable of permeating through cell membranes to react with the interior -S-H groups, rendering silver relatively nontoxic to humans and animals [25].

\section{Conclusion}

Antimicrobial BC-silver nanoparticles composite membranes were prepared using TEA as complexing and reducing agent and also plasticizer.

TEA molecules play a multifunctional role acting simultaneously as a strong reducing agent and good silver ions chelating agent, influencing the nucleation and particle growth, and hence particle size. TEA concentration is determinate in order to obtain only Ag particles and not a mixture of silver oxides, and TEA concentration was also observed to control particle size and amount of silver contents on to bacterial cellulose.

TEA also plays the role of plasticizer for the membranes as suggested from mechanical properties results. The new composite membranes exhibited a strong antimicrobial activity against Staphylococcus aureus (Gram-positive bacteria), Pseudomonas aeruginosa and Escherichia coli (Gram-negative bacteria), which are bacteria commonly found in contaminated wounds.

\section{Acknowledgments}

The authors acknowledge the financial support of the FAPESP, CAPES, and CNPq. They also thank LME/LNLS for technical support during electron microscopy work and the company Fibrocel-Produtos Biotecnológicos Ltda. for supplying the bacterial cellulose membranes.

\section{References}

[1] D. J. Gardner, G. S. Oporto, R. Mills, and M. A. S. A. Samir, "Adhesion and surface issues in cellulose and nanocellulose," Journal of Adhesion Science and Technology, vol. 22, pp. 545$567,2008$.

[2] H. S. Barud, C. A. Ribeiro, M. S. Crespi et al., "Thermal characterization of bacterial cellulose-phosphate composite membranes," Journal of Thermal Analysis and Calorimetry, vol. 87, no. 3, pp. 815-818, 2007.

[3] D. Klemm, D. Schumann, U. Udhardt, and S. Marsch, "Bacterial synthesized cellulose-artificial blood vessels for microsurgery," Progress in Polymer Science, vol. 26, no. 9, pp. 1561-1603, 2001.

[4] W. K. Czaja, D. J. Young, M. Kawecki, and R. M. Brown, "The future prospects of microbial cellulose in biomedical applications," Biomacromolecules, vol. 8, no. 1, pp. 1-12, 2007.

[5] C. Legnani, C. Vilani, V. L. Calil et al., "Bacterial cellulose membrane as flexible substrate for organic light emitting devices," Thin Solid Films, vol. 517, no. 3, pp. 1016-1020, 2008.

[6] T. Maneerung, S. Tokura, and R. Rujiravanit, "Impregnation of silver nanoparticles into bacterial cellulose for antimicrobial wound dressing," Carbohydrate Polymers, vol. 72, no. 1, pp. 4351, 2008.

[7] R. Jung, Y. Kim, H. S. Kim, and H. J. Jin, "Antimicrobial properties of hydrated cellulose membranes with silver nanoparticles," Journal of Biomaterials Science, Polymer Edition, vol. 20, no. 3, pp. 311-324, 2009.

[8] L. C. de Santa Maria, A. L. C. Santos, P. C. Oliveira, H. S. Barud, Y. Messaddeq, and S. J. L. Ribeiro, "Synthesis and characterization of silver nanoparticles impregnated into bacterial cellulose," Materials Letters, vol. 63, no. 9-10, pp. 797-799, 2009.

[9] B. S. Atiyeh, M. Costagliola, S. N. Hayek, and S. A. Dibo, "Effect of silver on burn wound infection control and healing: review of the literature," Burns, vol. 33, no. 2, pp. 139-148, 2007.

[10] H. S. Barud, C. Barrios, T. Regiani et al., "Self-supported silver nanoparticles containing bacterial cellulose membranes," Materials Science and Engineering C, vol. 28, no. 4, pp. 515518, 2008.

[11] B. R. Evans, H. M. O’Neill, V. P. Malyvanh, I. Lee, and J. Woodward, "Palladium-bacterial cellulose membranes for fuel cells," Biosensors and Bioelectronics, vol. 18, no. 7, pp. 917-923, 2003.

[12] I. W. Sutherland, "Novel and established applications of microbial polysaccharides," Trends in Biotechnology, vol. 16, no. 1, pp. 41-46, 1998.

[13] R. E. Cannon and S. M. Anderson, "Biogenesis of bacterial cellulose," Critical Reviews in Microbiology, vol. 17, no. 6, pp. 435-447, 1991.

[14] L. C. S. Maria, A. L. C. Santos, P. C. Oliveira et al., "Preparation and antibacterial activity of silver nanoparticles impregnated in bacterial cellulose," Polimeros, vol. 20, no. 1, pp. 72-77, 2010.

[15] T. Kocareva, I. Grozdanov, and B. Pejova, "Ag and AgO thin film formation in Ag-triethanolamine solutions," Materials Letters, vol. 47, no. 6, pp. 319-323, 2001.

[16] S. F. Wright, D. Dollimore, J. G. Dunn, and K. Alexander, "Determination of the vapor pressure curves of adipic acid and triethanolamine using thermogravimetric analysis," Thermochimica Acta, vol. 421, no. 1-2, pp. 25-30, 2004.

[17] S. Ifuku, M. Tsuji, M. Morimoto, H. Saimoto, and H. Yano, "Synthesis of silver nanoparticles templated by TEMPOmediated oxidized bacterial cellulose nanofibers," Biomacromolecules, vol. 10, no. 9, pp. 2714-2717, 2009.

[18] R. J. B. Pinto, P. A. A. P. Marques, C. P. Neto, T. Trindade, S. Daina, and P. Sadocco, "Antibacterial activity of nanocomposites of silver and bacterial or vegetable cellulosic fibers," Acta Biomaterialia, vol. 5, no. 6, pp. 2279-2289, 2009.

[19] M. Henriksson, L. A. Berglund, P. Isaksson, T. Lindström, and T. Nishino, "Cellulose nanopaper structures of high toughness," Biomacromolecules, vol. 9, no. 6, pp. 1579-1585, 2008.

[20] G. Guhados, W. Wan, and J. L. Hutter, "Measurement of the elastic modulus of single bacterial cellulose fibers using atomic force microscopy," Langmuir, vol. 21, no. 14, pp. 6642-6646, 2005.

[21] Y. C. Hsieh, H. Yano, M. Nogi, and S. J. Eichhorn, "An estimation of the Young's modulus of bacterial cellulose filaments," Cellulose, vol. 15, no. 4, pp. 507-513, 2008. 
[22] A. Retegi, N. Gabilondo, C. Peña et al., "Bacterial cellulose films with controlled microstructure-mechanical property relationships," Cellulose, vol. 17, no. 3, pp. 661-669, 2010.

[23] J. L. Audic and B. Chaufer, "Influence of plasticizers and crosslinking on the properties of biodegradable films made from sodium caseinate," European Polymer Journal, vol. 41, no. 8, pp. 1934-1942, 2005.

[24] L. Di Gioia, B. Cuq, and S. Guilbert, "Effect of hydrophilic plasticizers on thermomechanical properties of corn gluten meal," Cereal Chemistry, vol. 75, no. 4, pp. 514-519, 1998.

[25] J. R. Morones, J. L. Elechiguerra, A. Camacho et al., "The bactericidal effect of silver nanoparticles," Nanotechnology, vol. 16, no. 10, pp. 2346-2353, 2005. 

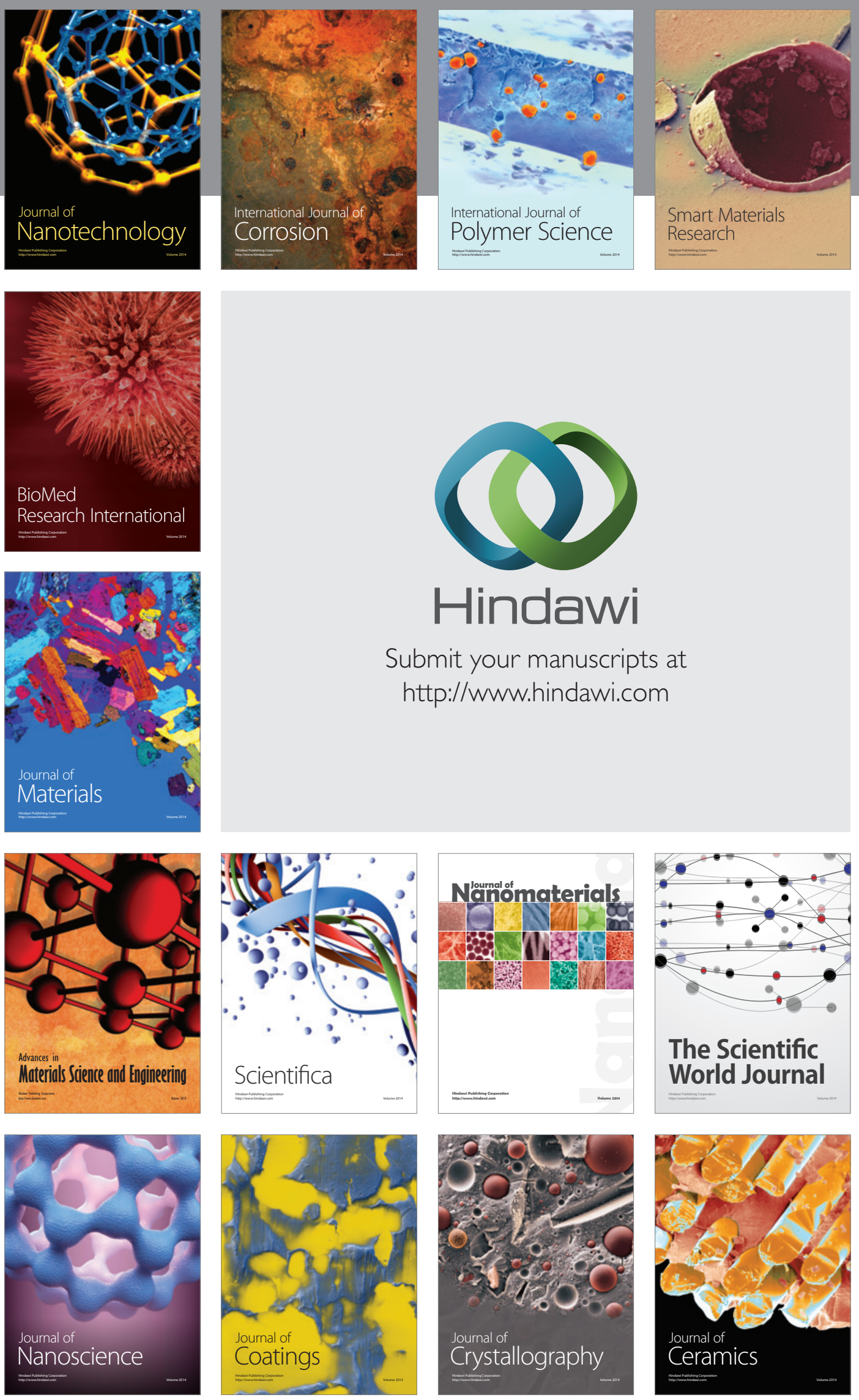

The Scientific World Journal

Submit your manuscripts at

http://www.hindawi.com

\section{World Journal}

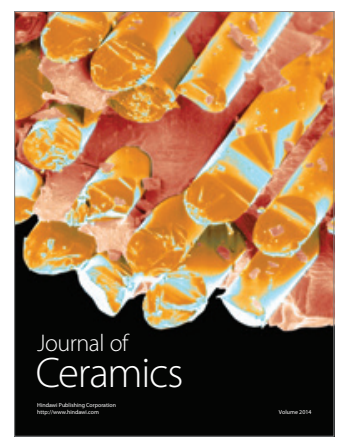

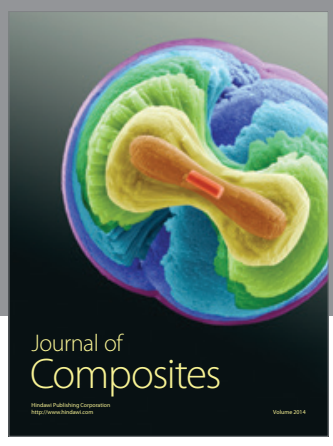
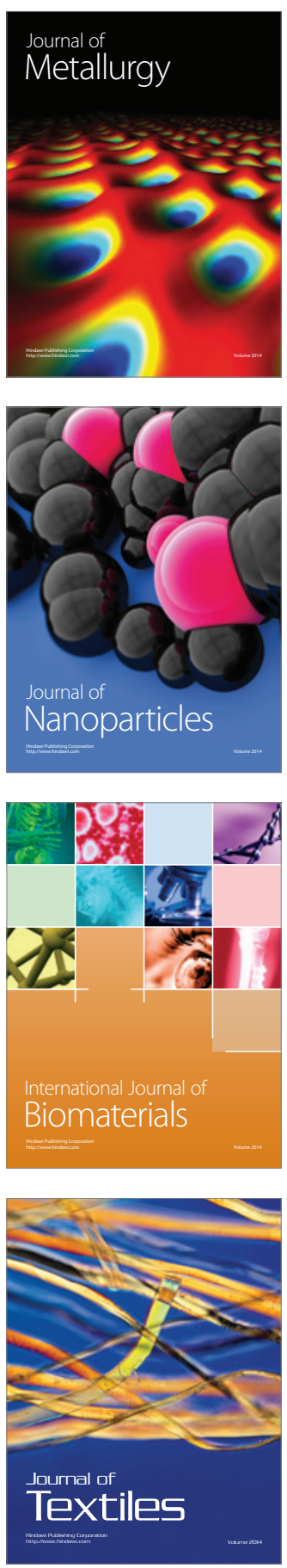